\title{
The measurement of climate change using data from the Advanced Very High Resolution and Along Track Scanning Radiometers
}

\author{
S. P. Lawrence, D. T. Llewellyn-Jones, and S. J. Smith \\ Department of Physics and Astronomy, Space Research Centre, University of Leicester, UK \\ Received 22 August 2003; revised 2 April 2004; accepted 20 May 2004; published 27 August 2004.
}

[1] Global sea-surface temperature is an important indicator of climate change, with the ability to reflect warming/cooling climate trends. The detection of such trends requires rigorous measurements that are global, accurate, and consistent. Space instruments can provide the means to achieve these required attributes in sea-surface temperature data. Analyses of two independent data sets from the Advanced Very High Resolution and Along Track Scanning Radiometers series of space sensors during the period 1985 to 2000 reveal trends of increasing global temperature with magnitudes of $0.09^{\circ} \mathrm{C}$ and $0.13^{\circ} \mathrm{C}$ per decade, respectively, closely matching that expected due to current levels of greenhouse gas exchange. In addition, an analysis based upon singular value decomposition, allowing the removal of El Niño in order to examine areas of change other than the tropical Pacific region, indicates that the 1997 El Niño event affected sea-surface temperature globally. The methodology demonstrated here can be applied to other data sets, which cover long time series observations of geophysical observations in order to characterize long-term change. The conclusion is that satellite sea-surface temperature provides an important means to quantify and explore the processes of climate change. INDEX TERMS: 1635 Global Change: Oceans (4203); 1640 Global Change: Remote sensing; 4294 Oceanography: General: Instruments and techniques; KEYWORDS: climate change, satellite data, sea-surface temperature

Citation: Lawrence, S. P., D. T. Llewelyn-Jones, and S. J. Smith (2004), The measurement of climate change using data from the Advanced Very High Resolution and Along Track Scanning Radiometers, J. Geophys. Res., 109, C08017, doi:10.1029/2003JC002104.

\section{Introduction}

[2] There is currently debate as to the extent of global climate change resulting from greenhouse gas concentrations in the atmosphere. There is evidence from a range of observational and model sources, which suggests that global climate change is enhanced by industrial pollution and that this is already impacting the Earth's climate [Houghton et al., 2001], although several authors suggest that natural dynamical influences could lead to decadal scale cooling/ warming phases [e.g., Hansen et al., 2001]. One conclusion of such studies is that current trends may be due more to natural variability, although Palmer [1999] and Corti et al. [1999] argue that the enhanced greenhouse effect could project on to natural modes of variability, making it difficult to determine the primary drivers of climate change.

[3] These and other investigations indicate that the relative impacts of the enhanced greenhouse effect and of natural variability are difficult to ascertain. In the face of this debate, there is a need for detailed, accurate observations that are global in nature, so that the true trend and associated spatial patterns can be identified, and that can also act as a rigorous test bed for model results. Such observations are provided by the Advanced Very-High

Copyright 2004 by the American Geophysical Union. 0148-0227/04/2003JC002104
Resolution Radiometers (AVHRRs), a series of infrared imaging space sensors whose data products are widely used for the accurate measurement of global sea-surface temperature (SST). The proposition that SST should be a surrogate for global change has been made in other studies [e.g., Allen et al., 1994]. Essentially, a climate trend should be reflected in SST, which in turn can be quantified using satellite data from the AVHRR instruments.

[4] Allen et al. [1994] showed that given currently expected changes in temperature, a climate trend could be identified to a level of $90 \%$ confidence after 15 years of measurement using global SSTs, providing the instrumental drift is less than about $0.02^{\circ} \mathrm{K}$ per decade. If the influence of natural phenomena such as El Niño could be removed from the data, this level of confidence can be increased, or else the timescale of data required can be reduced. Thus a prime consideration in work of this type is that the data set must be continuous and long term, suggesting an important reason for using AVHRR data. In this paper, we analyze 16 years of satellite SST data derived from AVHRR, in order to determine their merit in detecting global climate trends. Part of our methodology involves removing El Niño from the SST data set, using singular value decomposition, in order to investigate climate trends due to processes other than El Niño. For comparison, we have also performed a similar analysis with an independent set of measurements, provided by the European Space Agency's Along Track Scanning Radiometers 
(ATSR) series of satellite sensors. The ATSRs are infrared imagers with many similarities to AVHRR, but they use an SST retrieval methodology that is quite different than that employed for AVHRR. It will be seen that the results from AVHRR and ATSR are remarkably similar, indicating that the climate trend we have measured is largely independent of instrument or retrieval methodology, which provides a higher confidence in the results.

[5] The AVHRR and ATSR sensors are described in detail elsewhere [Schwalb, 1978, 1982; Kidwell, 1995; Cracknell, 1997; Edwards et al., 1990]. Briefly, they are both imaging radiometers in Sun-synchronous orbits, making measurements of top-of-the-atmosphere brightness temperatures at wavelengths of $3.7,11$, and $12 \mu \mathrm{m}$, with a spatial resolution, or pixel size, of $1 \mathrm{~km}$ square at the subsatellite point. Both sensors also have coregistered channels at visible or reflected infrared wavelengths, which are used to identify the presence of clouds by day. The principal differences between the two sensors are that ATSR employs a conical scanning method, whereby each terrestrial scene is viewed twice, at nadir and at approximately $55^{\circ}$ to nadir, within about $100 \mathrm{~s}$. This has the potential to achieve an improved atmospheric correction, especially in the presence of excessive atmospheric aerosol loading. There are also differences concerning calibration methodology, detector cooling, and other engineering aspects.

[6] In the case of both sensors, SST is retrieved as a linear combination of the directly measured brightness temperatures at the various wavelengths. Although the brightness temperatures are measured at very similar wavelengths, the derivation of the retrieval coefficients is very different, and each is quite independent of the other. The most important difference is that the AVHRR coefficients are derived by regression against in situ SST measurements, while the ATSR scheme relies instead upon historical atmospheric profile data and radiative transfer calculations. In this respect, the SST data provided by AVHRR and ATSR can be regarded as totally independent. In section 2 of this paper, we discuss the data briefly. In section 3 , we outline the methodology used to derive trends from the data, which is based upon the time series analysis of globally averaged SSTs from AVHRR and ATSR, and in section 4 we present the results. In section 4, we also detail a comparison between AVHRR and ATSR data; an interesting aspect of our work is a "proof of concept" analysis of climate change using SST from two major observing systems, in which it is useful to compare results from these systems to investigate whether any differences affect the climate change analysis. Indeed, throughout the discussion, we highlight this comparison as a key aspect of our work, although it must be stressed that the primary goal is to provide details of climatic trends in satellite data. We use the data intercomparison in an attempt to reduce any ambiguity or uncertainty in our results and to evaluate whether any global change we detect is due to the retrieval methodology or real climate processes. Finally, in section 5 we give the summary and conclusions.

\section{Sea-Surface Temperature Data From AVHRR and ATSR}

[7] The analysis described in this paper uses SST data issued by the National Oceanic and Atmospheric Adminis-
tration/National Aeronautics and Space Administration (NOAA/NASA) AVHRR Oceans Pathfinder Project [Kilpatrick et al., 2001] over the period January 1985 through to December 2000. These data are easily acquired from the Jet Propulsion Laboratory's (JPL) Physical Oceanography Distributed Active Archive Center (PO-DAAC) by $\mathrm{ftp}$. The AVHRR data record we have used consists of two channel data that have been reprocessed in a uniform way in which, after cloud-affected values have been identified and removed from the record, the SSTs have been retrieved using formulae based upon linear regression. The SST data are binned onto a regular $54 \mathrm{~km}$ in longitude by $54 \mathrm{~km}$ in latitude grid, starting at $89.75^{\circ} \mathrm{S}, 179.75^{\circ} \mathrm{W}$.

[8] We also use data from ATSR, obtained by ftp from the ATSR website (ftp://atsabt.ag.rl.ac.uk). These are daily data available for the period August 1991 through to April 1999, averaged onto a $0.5^{\circ} \times 0.5^{\circ}$ grid, with cloud-affected data points removed from each grid box, as with AVHRR. We use two-channel ATSR-2 SSTs retrieved from channels at $11 \mu \mathrm{m}$ and $12 \mu \mathrm{m}$, which, due to the failure of the 3.7- $\mu \mathrm{m}$ channel on ATSR-1 early in the mission, provides some consistency of retrieval between ATSR-1 and ATSR-2, avoiding any issues concerning the different characteristics of two-channel and three-channel retrieval schemes.

[9] The objective of this paper is to investigate trends in SST. As indicated earlier, one component of the methodology is to compare data from two independent spaceborne sensors. Therefore, for consistency throughout, we use daytime data from AVHRR, which provide a sensible and logical correspondence with the two-channel ATSR data that we are using. The use of nighttime AVHRR data, or mixed day-night data, may introduce a time-varying bias, which it would be difficult to account for in our analysis.

[10] Although using a two-channel algorithm, the ATSR data stream includes both daytime and nighttime data, so it is possible that day-night SST differences could depress the mean temperatures derived from ATSR data. Similarly, AVHRR equatorial crossing times are typically at 13.30 and 19.30 , so that some diurnal variation would be anticipated. However, it will be seen that the analysis presented here has been designed to extract trends from the time series and that the results are unaffected by small systematic biases between the observing systems, as described in section 4 .

[11] In this investigation, all data are monthly averaged. An example of a typical global map of SST from AVHRR is shown in Figure 1. Figure 1a shows the map for December 1996. The AVHRR provide a large amount of detail as can be seen for example in the Gulf Stream region of the North Atlantic and in the South Atlantic off the coast of Argentina. In addition, the east Pacific cold tongue exhibits tropical instability waves that remain even after averaging over a month. Figure $1 \mathrm{~b}$ shows the corresponding map for December 1997. The significant difference between this map and that shown in Figure 1a is the absence of the east Pacific cold tongue, indicative of the 1997 El Niño event.

[12] An important feature of Figure 1 as regards this analysis is the presence of persistent cloud over a whole month as represented by missing data, particularly off the west coasts of Africa and South America. The areas over which such cloud persists varies from month to month and from year to year, and this variability must be taken into 

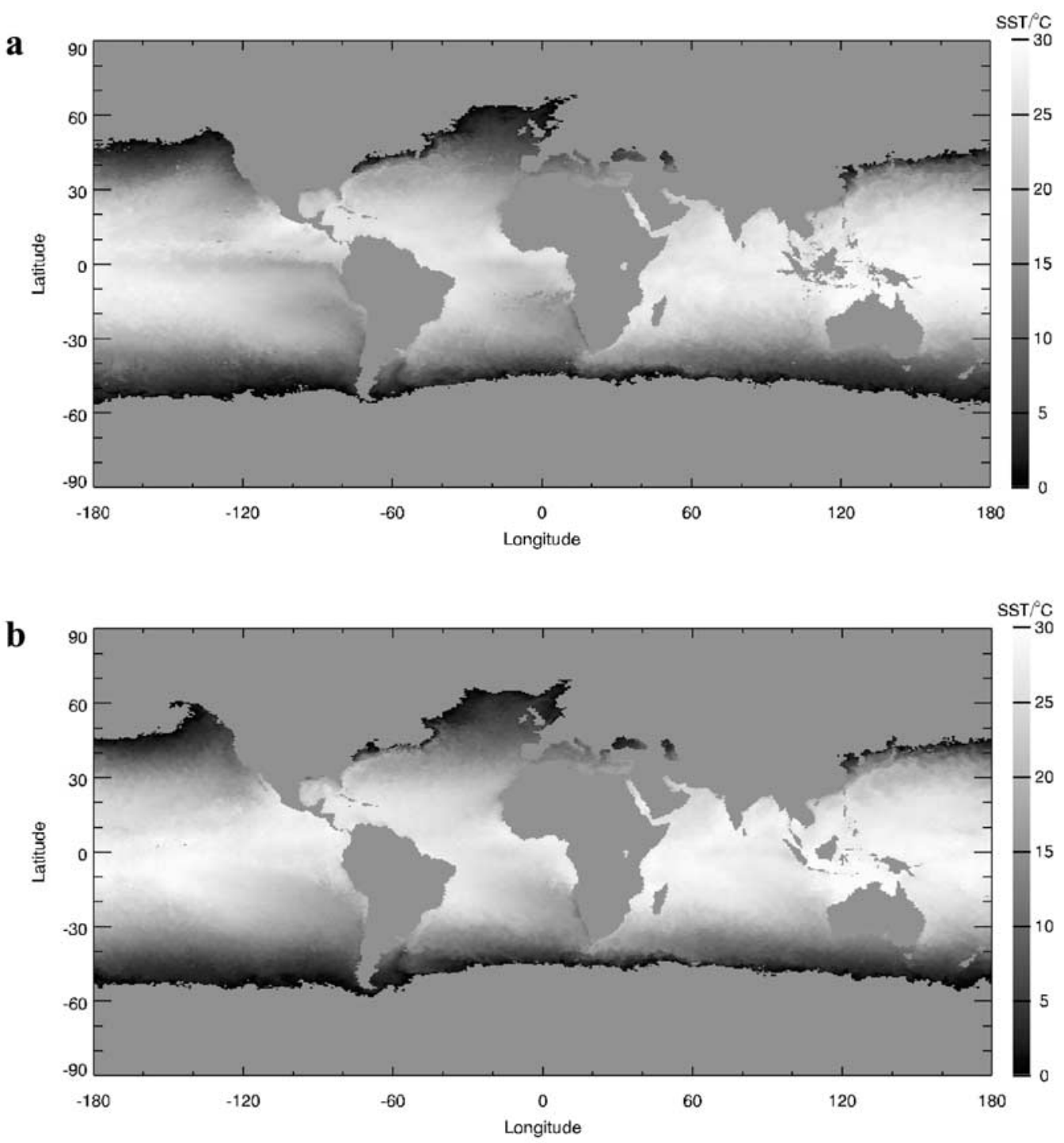

Figure 1. Sea-surface temperature from AVHRR for (a) December 1996 and (b) December 1997. The color bar scale is in ${ }^{\circ} \mathrm{C}$. See color version of this figure in the HTML.

account in any time series analysis in order to have continuous data over each $54 \mathrm{~km} \times 54 \mathrm{~km}$ grid box.

[13] In addition to continuity of data, a factor to consider in a trend analysis based upon satellite data is the consistency of the record across the series of instruments that are used to make up the data stream. In the case of AVHRR, a great deal of effort has been employed to ensure a reliable product, through the AVHRR Oceans Pathfinder program. Consistent retrieval and cloud-clearing algorithms have been applied [Kilpatrick, 2001; Rao, 1993; Vasquez et al., 1996], and the archived data were reprocessed using a nonlinear algorithm, to lower any biases [Evans and Podesta, 1996].

[14] When considering ATSR data, this series of instruments are self-calibrating, and no evidence has been reported to suggest that there exist significant time-varying instrumental biases. There are minor differences in retrieval schemes for ATSR-1 and ATSR-2, which concern some refinements in the radiative transfer calculations used to derive the retrieval coefficients and some improvements in the cloud-clearing algorithms used in the respective retrieval schemes. These differences give rise to biases that are small compared to the large-scale fluctuations that we consider in this paper and are either random or seasonal in nature.

[15] The orbits of the ERS1 and ERS2 satellites are maintained to be sun synchronous with a nominal equatorial crossing time of 1030 and 2230 local time. Any occasional variations in this crossing time amount to minutes rather than hours and therefore are insufficient to introduce any spurious trend signals based on diurnal variation of SST. The possibility of instrumental drift affecting the ATSR time series has been considered and is unlikely to be significant since, as described by Edwards et al. [1990], the ATSR instruments each have two onboard blackbody targets, held respectively at two temperatures, one at each extreme of the instrument's measuring range. These targets are carefully designed and well monitored, so that their degradation is detectable. 


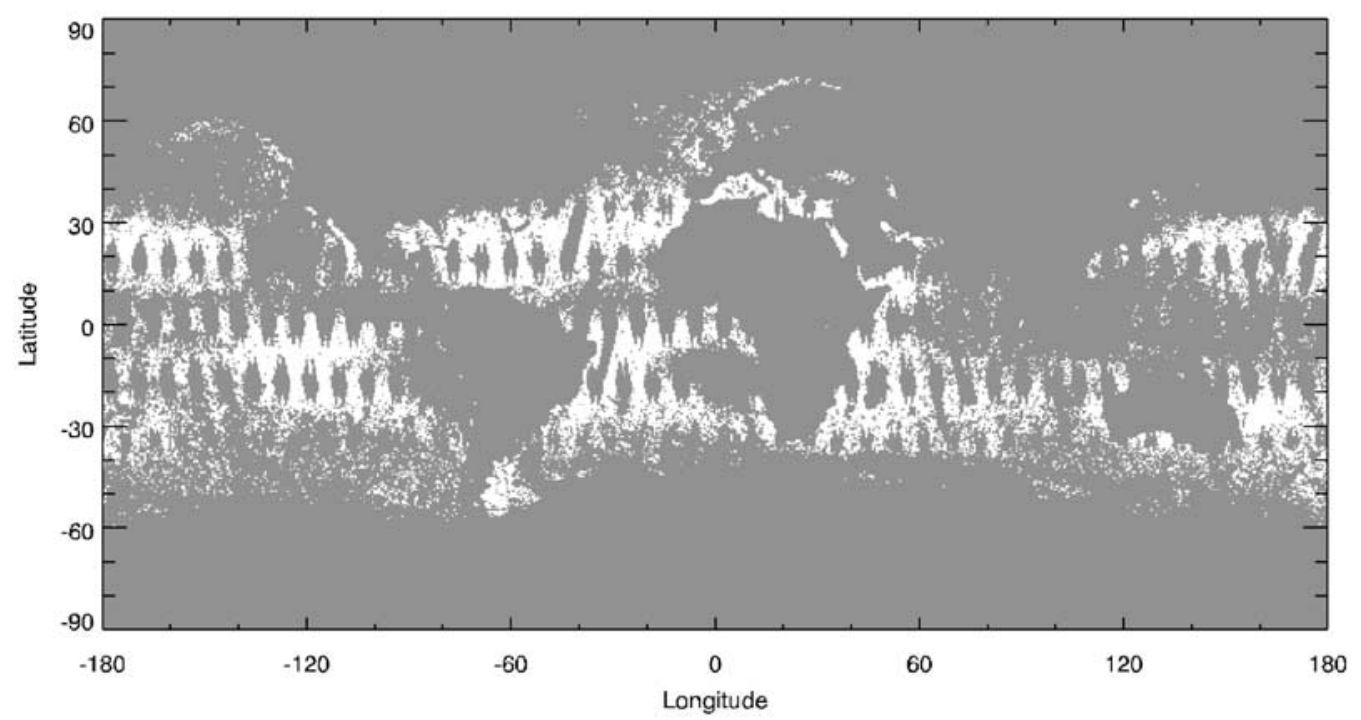

Figure 2. Master mask obtained from ATSR data. In constructing the mask, data values that are missing for any one month are defined to be missing for the whole time series. The dark shading indicates land or missing data, and the light shading represents regions where a surface temperature can be defined for the whole time series.

[16] Therefore we assume that any bias between ATSR-1 and ATSR-2 is constant in time, or else is seasonal in nature. In both cases, our methodology ensures that differences between ATSR-1 and ATSR-2 are eliminated to first order from the analysis. We present evidence for this in section 4, when we consider the SST anomalies derived from AVHRR, ATSR-1, and ATSR-2.

\section{Analysis}

[17] The procedure is to use monthly average data on a regular grid, as described in section 2 . We average these data globally and calculate a linear trend in this global average, after removing the signal due to the seasonal cycle and El Niño, using techniques described in sections 3.3. Before performing this analysis, several preliminary steps are required, as outlined in sections 3.1 and 3.2.

\subsection{Constructing a Land-Sea Mask}

[18] A trend analysis of the type outlined in this paper requires continuous data for each grid box. In order to guarantee this, we use the condition that if a grid-box has a missing data value for any month, then data from that grid box are discarded for all months in the data stream. The result is a "master mask" that has a value 0 over land or missing data and a value 1 over ocean. Once a master mask has been constructed, each grid box in the data stream is multiplied by the corresponding mask value to yield a constant, time-invariant mask for each monthly average data point.

[19] The criterion that a data value is missing for the whole record may be too rigorous for an investigation of the type performed here, especially when using ATSR data. In this case, only $12 \%$ of data points remain as SST values useful in the trend analysis as illustrated in Figure 2, which shows the master mask generated from almost an 8-year record of $0.5^{\circ} \times 0.5^{\circ}$ gridded ATSR data corresponding to
259,200 potential SST grid boxes for each month. Here the dark shading represents land or missing data, and the light shading indicates areas that have an SST value for all months. Using this master mask, it would be impossible to ascribe a trend to particular regions of the globe, since the relatively few data points that remain occur predominantly within the tropics.

[20] In contrast to ATSR, AVHRR exhibits fuller coverage over the 16 years of data considered here compared with that for ATSR data over approximately 8 years. This could be due to a number of factors, including AVHRR's wider swath width, or the intrinsic rigor and efficiency of the respective cloud identification procedures used in the data processing schemes, combined with the radiometric sensitivity of either sensor to marginal quantities of cloud at the $1-\mathrm{km}$ pixel level. Nevertheless, only $31 \%$ of grid boxes remain continuously cloud free in AVHRR data, and again an analysis of global patterns of change would not be possible using these data with the master mask.

[21] The coverage does not significantly affect the climate change calculations discussed here since the large areas of the tropical regions, where both ATSR and AVHRR data exhibit the most extensive coverage, dominate a globally averaged SST field. As a result of this, our time series analysis of global averaged SST, to be outlined later, is unaffected by the choice of master mask, within reasonable limits. Nevertheless, in order to explore patterns of change at higher latitudes, we spatially averaged each monthly field onto a coarser $2.5^{\circ} \times$ $2.5^{\circ}$ grid using simple averaging over $250.5^{\circ}$ grid boxes. This results in a wider regional coverage of data, with the caveat that data points close to cloudy pixels could themselves include some cloud contamination and a bias could subsequently be carried through into the global average. Nevertheless, for consistency throughout our exploration of climate trends, we use $2.5^{\circ}$ data. As an alternative to the above approach, one could employ a simple linear interpolation in time, in order to fill the data. We decided not to do 


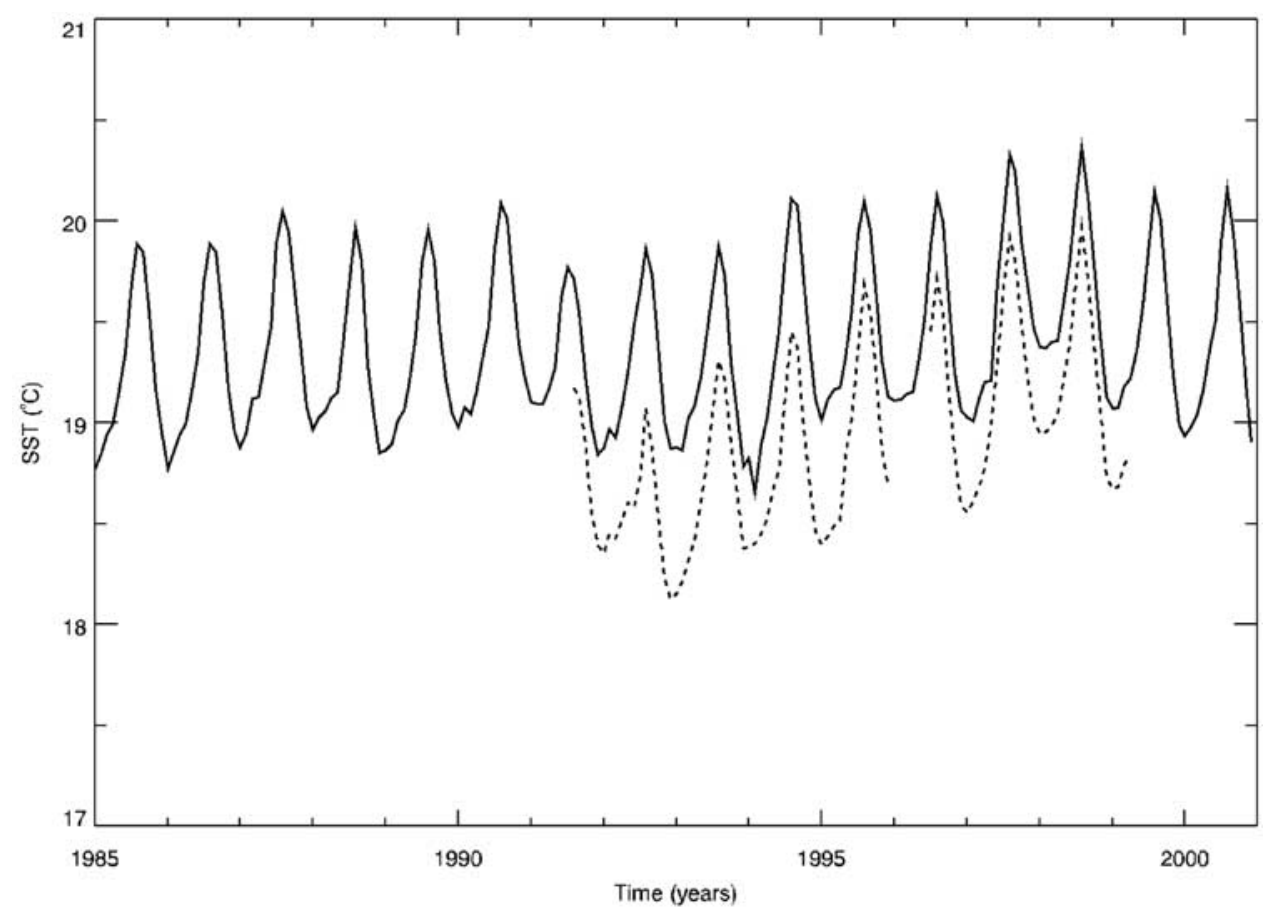

Figure 3. Time series of globally averaged sea-surface temperature from AVHRR (solid line) and ATSR (dashed line).

this since we felt that biases could be introduced, especially when interpolating through long gaps in data.

[22] Finally, it may be worth pointing out that one could relax the criterion of demanding full continuity of data by requiring a certain proportion, say $80 \%$, of the grid boxes to be cloud free. However, such a criterion would, by its nature, be arbitrary, although a parametric analysis of the effects of applying such an upper limit on data availability could be undertaken, together with a statistical confidence analysis. We have not performed such an analysis and instead have used the rigorous requirement of $100 \%$ coverage at each grid box.

\subsection{Globally Averaged Data}

[23] We perform a time series analysis of climate trends using globally averaged SST data. This average is generated in two stages: First, each $2.5^{\circ}$, or $270-\mathrm{km}$ latitude band, is zonally averaged, and second, each zonal average is summed and divided by the total number of latitude bands that contain valid data. In the case of ATSR, an additional stage of area weighting in latitude is employed.

[24] Figure 3 shows the global average for AVHRR data for the period 1985 to 2000 (solid line) and ATSR data for the period August 1991 through to April 1999 (dashed line). Over the period of ATSR data, the correlation between ATSR and AVHRR SSTs is 0.92 , indicating that the seasonal variation (the dominant variability in SST) is captured fairly consistently in AVHRR and ATSR. Note that due to technical problems with the sensor, data points during the first 6 months of 1996 are missing from the ATSR time series.

\subsection{Removing the Seasonal Cycle and EI Niño}

[25] To examine climate trends, we analyze data obtained by removing the seasonal cycle and El Niño from the global average SST. The result is an anomaly field that describes climate trends due to processes other than these two most dominant modes of variability, including the enhanced greenhouse effect and natural variability due to, for example, a coupling with the North Atlantic Oscillation, of which there is evidence in figures not shown in this paper. Similar procedures were carried out by Christy and McNider [1994] and Wigley [2000] using global data, and in regional studies by Salinger et al. [1995] and Zheng et al. [1997]. In this paper, we use a different methodology to produce SST anomalies, based upon singular value decomposition.

[26] The seasonal cycle was calculated by averaging over all Januarys, Februarys, etc. A more sophisticated technique based on spectral analysis yielded a seasonal cycle with spectral components very similar to those provided by simple averaging, indicating that the calculation of a seasonal cycle by an averaging approach is adequate.

[27] We remove El Niño by linear regression of the time series at each data-point onto modes derived from a singular value decomposition (SVD) of SSTs from the tropical Pacific region. Providing that we have removed the seasonal cycle adequately, the dominant mode (first column of the EOF matrix and first row of principal component matrix) should represent El Niño. Figure 4 shows the resultant first EOF (Figure 4a) and first principal component (Figure 4b) for AVHRR data. The large signal in the eastern tropical Pacific (Figure 4a) and dominant peaks during 1987 and 1997 (Figure 4b) are representative of El Niño.

[28] A linear regression between the SST anomaly time series and the first principal component yields regression constants $a_{m n}$ and $b_{m n}$ at each spatial grid point $\left(x_{m}, y_{n}\right)$ 

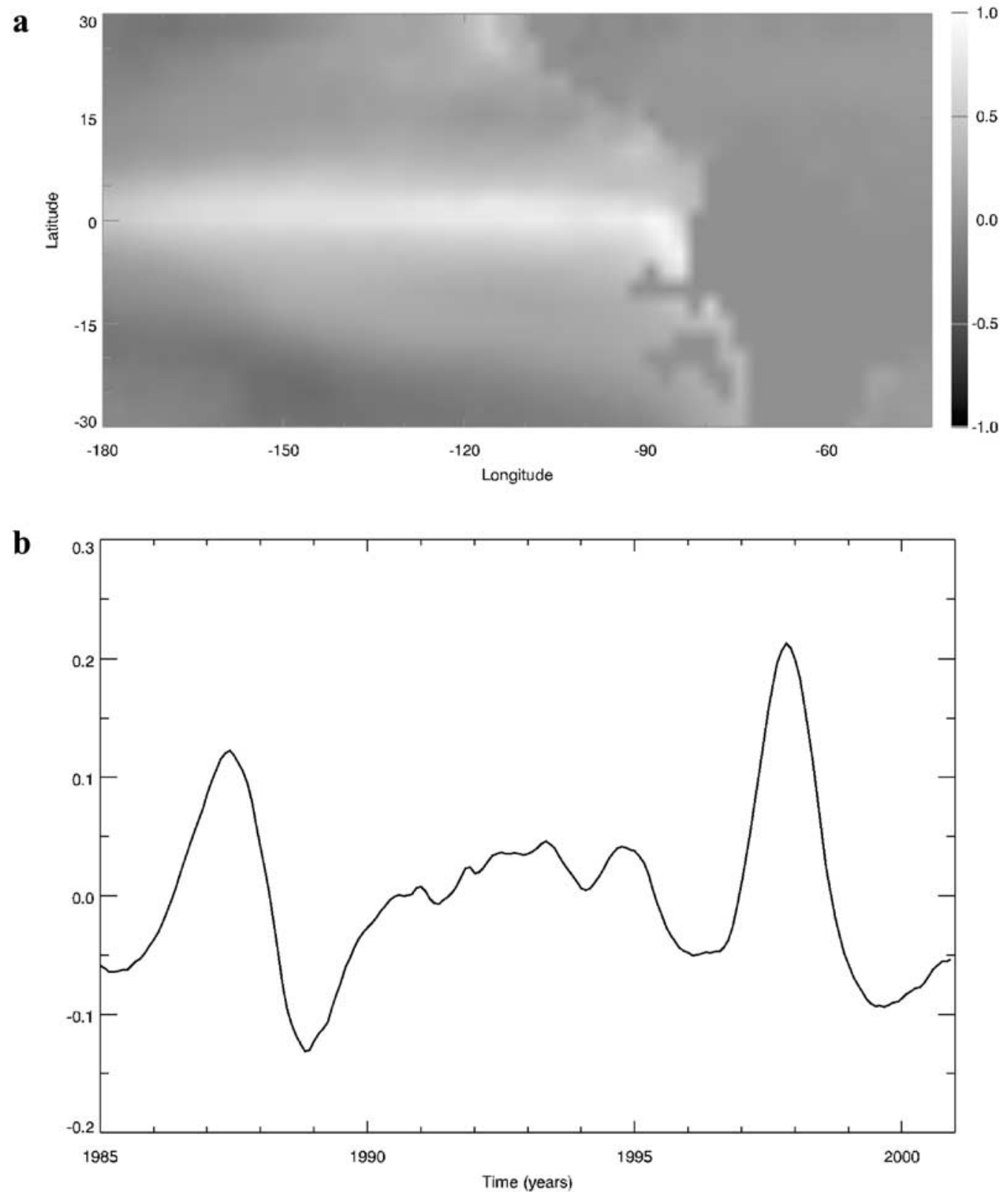

Figure 4. (a) First empirical orthogonal function for AVHRR data, obtained by singular value decomposition of tropical Pacific SSTs, in the latitude range $30^{\circ} \mathrm{S}$ to $\sim 30^{\circ} \mathrm{N}$ and $120^{\circ} \mathrm{E}$ to $60^{\circ} \mathrm{W}$. (b) Corresponding time series (principal component). Variability due to El Niño is evident in both plots as a high-amplitude signal. The color bar scale in Figure 4a is arbitrary. See color version of this figure in the HTML.

which are used to determine the El Niño signature associated with the SST anomalies

$$
T_{m n k}^{\mathrm{ENSO}}=a_{m n} P_{1 k}+b_{m n},
$$

where the subscripts $m$ and $n$ relate to the grid point $\left(x_{m}, y_{n}\right)$, the subscript $k$ represents time, and $P_{1 \mathrm{k}}$ represents the first principal component.

[29] Subtracting $T_{m n k}^{\mathrm{ENSO}}$ from the SST at each location with seasonal cycle already removed $\left(T_{m n k}\right)$ yields an SST anomaly with El Niño subtracted,

$$
\hat{T}_{m n k}=T_{m n k}-T_{m n k}^{\mathrm{ENSO}},
$$

where $\hat{T}_{m n k}$ is the required anomaly data at the spatial grid point $\left(x_{m}, y_{n}\right)$ that provides trends due to processes other than the seasonal cycle and El Niño.

[30] Note that this procedure is similar to that followed by Enfield and Mestas-Nunez [1999], except that these authors used global data to determine their empirical orthogonal function (EOF) patterns and principal components. In that case, it is necessary to employ complex EOFs, since El Niño could contaminate the lower modes of the ordinary EOFs. In our investigations, an ordinary EOF analysis is possible since we evaluate the modes from the tropical Pacific region only, where El Niño is by far the most important mode of variability. Certainly, there is no obvious signature of $\mathrm{El}$ Niño in the lower EOFs and principal components. 


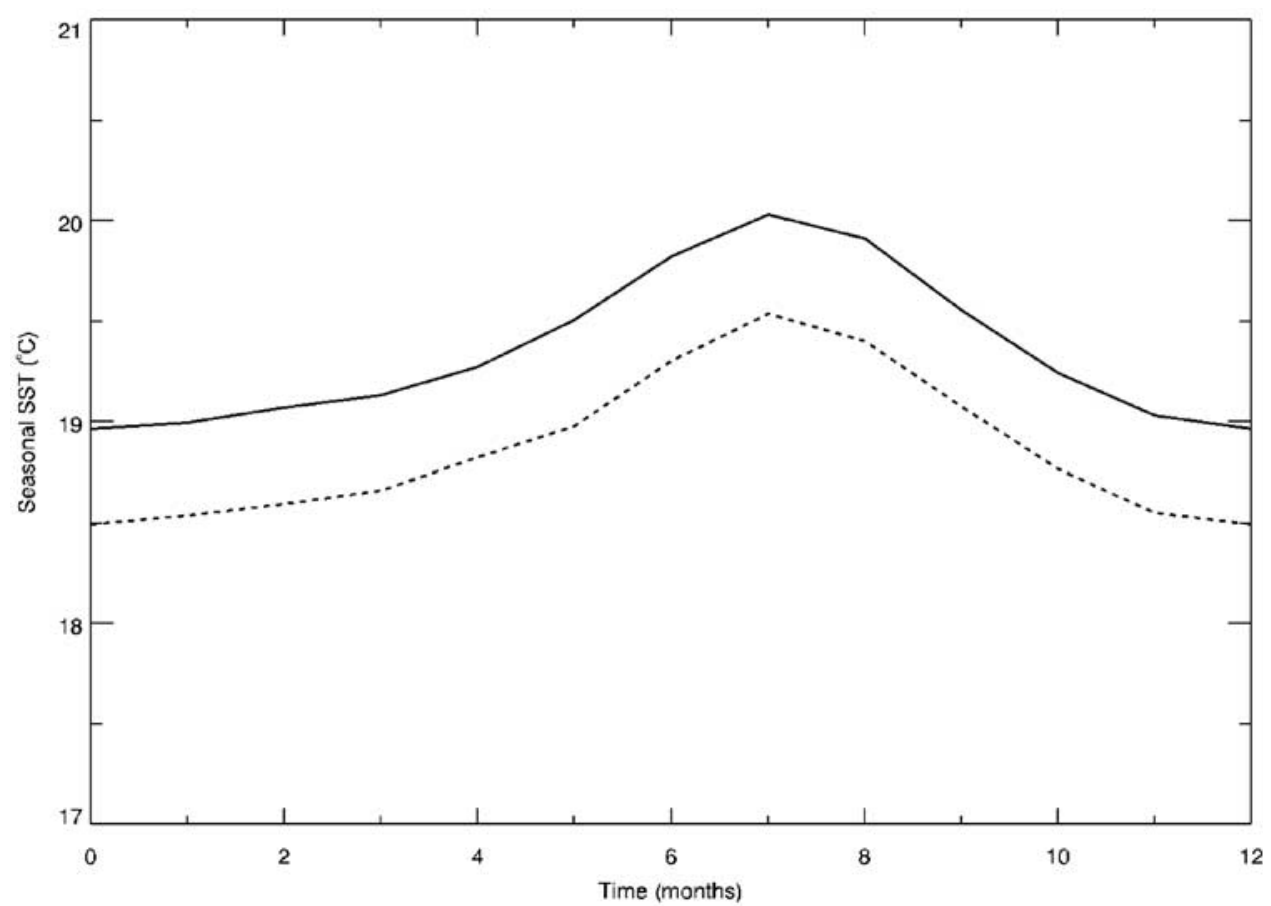

Figure 5. Seasonal cycles for AVHRR (solid line) and ATSR (dashed line) obtained from simple averaging. The seasonal cycles are in phase and have similar amplitude, indicating some consistency between these instruments.

[31] Once we have removed the seasonal cycle and El Niño, the analysis of trends is a straightforward linear regression onto the SST global average. In the remainder of this paper, we provide results from a time series analysis, leaving an analysis of patterns of change to a later paper.

\section{Results}

[32] In what follows, we describe the results of globally averaging AVHRR and ATSR SSTs, as the basic step required to obtain an estimate of a global SST trend. The discussion is broken down into subsections, in which we first outline the characteristics of the seasonal cycle, and then go on to describe SST anomalies for the two space sensors. Part of the process of our analysis involves a comparison between AVHRR and ATSR time series, in order to elucidate whether a consistent trend can be found in data from these independent measurement systems, or to determine whether any trend detected is seriously affected by the different SST retrieval methods employed for the two sensors. It is useful to detail this comparison between results from AVHRR and ATSR, in order to bring extra confidence in the trend estimates outlined in section 4.4. Finally, in this section, we describe the possible impact of the 1997 El Niño event upon the global sea-surface temperature field, in an initial analysis of the spatial patterns of climate change.

\subsection{Seasonal Cycle}

[33] As described above, we calculate globally averaged SST to determine the global trend. The SST field exhibits an asymmetry between the Northern and Southern Hemisphere due to the presence of landmass and axial tilt. Therefore the seasonal cycle shows up in the global averages, as illustrated in Figure 3.
[34] Figure 5 shows the seasonal cycles calculated using basic averaging, as described in section 3, using AVHRR (solid line) and ATSR (dashed line) global averages. The seasonal cycle is very consistent between these two instruments, with a correlation of greater than 0.99 and amplitudes of $1.07^{\circ} \mathrm{C}\left(\right.$ AVHRR) and $1.06^{\circ} \mathrm{C}$ (ATSR). There is an offset of $0.47^{\circ} \mathrm{C}$ between the two seasonal cycles, possibly reflecting differences in the SST retrieval technique used; for example, the AVHRR retrieval is derived from statistical regression against in situ bulk SST data, while those for ATSR are physically based using a radiative transfer model and atmospheric profile data resulting in the retrieval of the skin SST from the ATSR sensors. The skin SST is expected, when averaged, to be consistently lower than the bulk temperature by several tenths of a degree [Donlon et al., 1999], which could indeed account for the AVHRR/ATSR SST differences. Alternatively, the use of daytime data only from AVHRR, in contrast to ATSR where some nighttime data are used, could have introduced a diurnal bias that will be seasonal in nature. However, any differences between AVHRR and ATSR are taken into account when the seasonal cycle is removed, as we discuss later. If the mean offset is removed the maximum difference between AVHRR and ATSR seasonal cycles is approximately $4 \%$ of the amplitude in the seasonal cycle.

[35] We also compared the seasonal cycles derived separately for ATSR-1 and ATSR-2. The correlation between these is also greater than 0.99 . The seasonal cycles exhibit an average offset of approximately $0.5^{\circ} \mathrm{C}$, possibly because the 1991 Pinatubo eruption gives rise to a cooler seasonal cycle when using ATSR-1 data, while the 1997 El Niño event leads to the calculation of a warmer seasonal cycle from ATSR-2. If this offset is taken into account in comparing the seasonal cycles derived from ATSR-1 and 


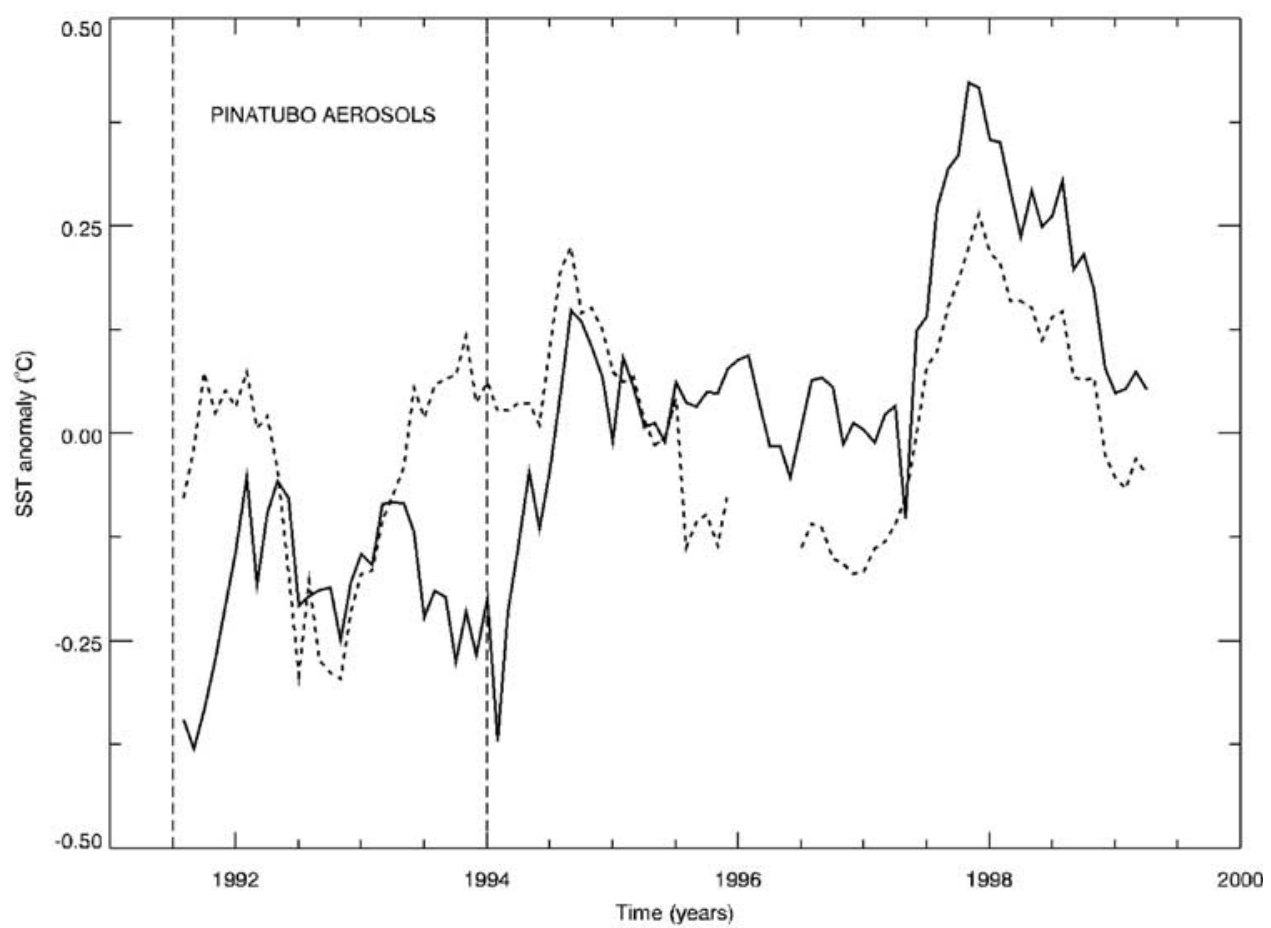

Figure 6. Time series of sea-surface temperature anomaly after removal of the seasonal cycles, for AVHRR (solid line) and ATSR (dashed line). The anomalies exhibit similar behavior, especially during 1996-1999. Prior to this period, Mount Pinatubo aerosols contaminate the data during the period indicated by vertical dashed lines.

ATSR-2, we obtain an average difference of $0.04^{\circ} \mathrm{C}$. Andersen et al. [2002] noticed a similar offset.

[36] The fact that the seasonal cycles derived from an averaging process are consistent across the individual instruments and measuring systems provides some evidence that there is limited bias in the time series associated with the globally averaged SST field. Any bias that does exist shows up as a constant offset between the various data sets, possibly due to differences between the retrieval schemes. In the case of ATSR-1 and ATSR-2, the seasonal cycle derived across the full-range time series of ATSR data is consistent with that obtained from ATSR-1 or ATSR-2 alone, but offsets will be introduced into the calculation of temperature anomalies if the full-range seasonal cycle is used to calculate the ATSR SST anomalies. In what follows, when considering ATSR data, we derive seasonal cycles separately for the two instruments from the freely available data. That is, for ATSR-1, a seasonal cycle is calculated from data during August 1991 through to May 1995, and for ATSR-2 from data during June 1995 through to April 1999.

\subsection{SST Anomalies}

[37] Figure 6 shows the anomaly data that result from removal of the seasonal cycle, for AVHRR (solid line) and ATSR (a dashed line is used for ATSR-1 and a dash-dotted line for ATSR-2), using the respective seasonal cycles to generate anomalies for ATSR-1 and ATSR-2. A spectral analysis reveals no significant power at the annual period, so we conclude that the seasonal cycle has been satisfactorily removed from these data. At first glance, the two curves in Figure 6 look substantially different over the period of
ATSR data. However, closer inspection reveals some similarity. During 1991-1993, both data sets show substantial cooling due to the Mount Pinatubo eruption, as indicated by vertical dashed lines in Figure 6, which reduces the SST anomaly due to the extended El Niño during that period. The ATSR time series seems to "recover" more quickly than AVHRR, although it is perhaps difficult to suggest conclusively that either data set records an accurate SST during this time. We discuss the effects of Pinatubo aerosols further in the next section. From June 1994 to July 1995, the ATSR-1 and AVHRR anomalies follow each other very closely, at which point the ATSR-1 time series ends.

[38] Consideration of the period after the Pinatubo eruption appears to affect the data; that is, about March 1994 onward yields a correlation between the AVHRR and ATSR data of 0.6 , indicating good agreement between these instruments. Choosing a period July 1994 to the end of the ATSR data yields an increased correlation of 0.65 , rising to 0.9 or higher for various periods between 1995 through to 1999 . These high correlations indicate that AVHRR and ATSR anomalies are in phase with one another overall.

[39] During the period August 1996 to April 1999, AVHRR anomalies are $0.15^{\circ} \mathrm{C}$ warmer than ATSR on average, with a correlation of 0.9 indicating the broad correspondence in temperature anomaly between the two independent data sets. Inspection of Figure 6 during this period indicates that the basic structure of the two data sets follows the same pattern, with rises in AVHRR data being reflected closely by ATSR, on the whole, particularly during the 1997/1998 El Niño event, until April 1999, when the ATSR-2 time series ends. 
[40] The $0.15^{\circ} \mathrm{C}$ bias between AVHRR and ATSR apparent during the period of ATSR-2 may be due to a diurnal cycle, which would lower the monthly average temperature in ATSR-2 relative to AVHRR. However, it would be supposed that this should affect the ATSR-1 time series in a similar way. We expect the diurnal cycle to have a seasonal element, which will feed into the calculation of the seasonal cycle. Therefore, the diurnal cycle should be eliminated (to a certain extent) when the seasonal cycle is removed. The fact that there is no evident ATSR-1/AVHRR bias up to the end of the ATSR-1 series in May 1995 (apart from differences resulting from Pinatubo aerosols) seems to indicate that the diurnal cycle has been removed adequately from the ATSR data stream, through the removal of the seasonal cycle. As a check, we compared anomalies from AVHRR nighttime and daytime data. We find no timedependent change between these two data sets, indicating again that there is no diurnal cycle evident in our data that could influence our trend analysis. However, as pointed out earlier, we want to be sure that differences between twochannel and three-channel retrievals do not influence our analysis of global SST trends, and it is for this reason that we use daytime AVHRR data throughout.

[41] If we compute the AVHRR seasonal cycle using data over the period of ATSR-2 operation, that is, June 1995 to April 1999, we find that AVHRR anomalies during this period are $0.15^{\circ} \mathrm{C}$ cooler on average than those obtained from AVHRR when using the period August 1991 to April 1999 (that is, the total range over which we have ATSR data). Therefore we conclude that the ATSR-2/AVHRR cool bias occurs not because of any diurnal variability, which may result from the use of day-night data, but rather because a warm seasonal cycle has been subtracted from ATSR-2 globally averaged SSTs, due to a warm bias from the 1997 El Niño, leading to cool anomalies for ATSR-2.

[42] These points are important because a diurnal cycle could manifest itself as a climate trend, especially when several instruments are involved, as is the case here. In this investigation, we conclude that any diurnal variations are eliminated during the removal of the seasonal cycle, leaving at most a constant offset in both AVHRR and ATSR data sets. The case for a comparison between instruments is made stronger, since we can effectively determine any bias introduced by any diurnal/seasonal variations in ATSR data through comparison with AVHRR, yielding time series from these two sensors that are consistent with each other.

[43] The fact that ATSR and AVHRR temperature anomalies are very similar throughout the post-Pinatubo period, with correlations greater than 0.6 , indicates that to a constant offset, globally averaged ATSR-1 and ATSR-2 SST anomalies are also consistent with one another. This provides evidence to suggest that our analysis methodology is appropriate and that any climate trends we detect are not due to inconsistencies in the ATSR retrievals, supporting the arguments outlined in sections 2 and 3 that we can treat ATSR data as a single time series providing we remove the appropriate seasonal cycle separately from each instrument.

[44] There is a distinct value in comparing AVHRR and ATSR data in that analyses for these two types of instrument are essentially independent, so that similarities in results could be indicative of true warming or cooling variations. Certainly, an analysis of this type avoids problems associ- ated with merged data sets, as highlighted by Hurrel and Trenberth [1997], or with inconsistencies in retrievals, whether for the same instrument or for a series. The major errors and differences between ATSR and AVHRR seem to derive from the way the retrievals deal with the Mount Pinatubo eruption so that, in any case, a merged data set would not necessarily yield new information during that period.

\subsection{Comparison With In Situ Data}

[45] In section 4.2, we discussed similarities between AVHRR and ATSR. The conclusion is that there is good agreement between the time series, particularly postPinatubo. It is also useful to compare with in situ data as a further check on the satellite data, particularly during Pinatubo when AVHRR and ATSR data differ most substantially. For this purpose, we use data from the Comprehensive Ocean-Atmosphere Data Set (COADS) [Woodruff et al., 1987] for the period 1985-1997.

[46] Figure 7 shows globally averaged data from AVHRR (solid line) and from COADS (dashed line). The first point to note is that variations in COADS and AVHRR agree well, with a correlation of 0.71 between these data over this 13-year period. The ATSR data (not shown in this figure) agree less well with COADS, but nevertheless the correlation is 0.61 .

[47] The AVHRR and COADS anomalies agree well during 1991-1993 (i.e., during the contamination by Pinatubo aerosols highlighted in section 4.2), with a correlation coefficient of 0.7 possibly resulting from the changes to the algorithm coefficients that were made in order to deal with Pinatubo aerosols. The AVHRR anomalies begin to fall during January 1991, at about the same time as COADS, but remain positive. In both data sets the anomalies rise slightly during March-June 1991, before becoming negative during October 1991, due to cooling by Pinatubo aerosols. In the case of AVHRR data, this is the minimum anomaly in the whole time series with a value of $-0.36^{\circ} \mathrm{C}$, less than the COADS value of $-0.16^{\circ} \mathrm{C}$ for the same point. From December 1991 to spring 1992, the anomalies rise again due to the 1991/1992 El Niño and then, as El Niño decays, the anomalies in both data sets decrease to $-0.23^{\circ} \mathrm{C}$ (AVHRR) and $-0.21^{\circ} \mathrm{C}$ (COADS) during November 1992. The AVHRR recovery from negative toward zero anomaly occurs during January 1994, slightly prior to rises in the COADS anomaly.

[48] The net temperature decrease in COADS data from April 1990 (i.e., the maximum in COADS anomalies during $1990 / 1991)$ to October 1991 is $0.34^{\circ} \mathrm{C}$, whereas the AVHRR data show a decrease of $0.45^{\circ} \mathrm{C}$ over a similar period. Note that aerosols could lead to a negative bias in AVHRR data as pointed out by Reynolds et al. [2002] and Zhang et al. [2004], who suggest that regions of low AVHRR SSTs are likely to be associated with aerosol contamination. Given the uncertainty in these measurements, a conclusion from this comparison between AVHRR and COADS may well be that AVHRR is recording a realistic cooling of the climate during 1991-1993 due to the Pinatubo eruption.

[49] Subsequent to Pinatubo, from January 1994 to December 1997, the AVHRR and COADS anomalies follow each other very closely, with a correlation of 0.8 


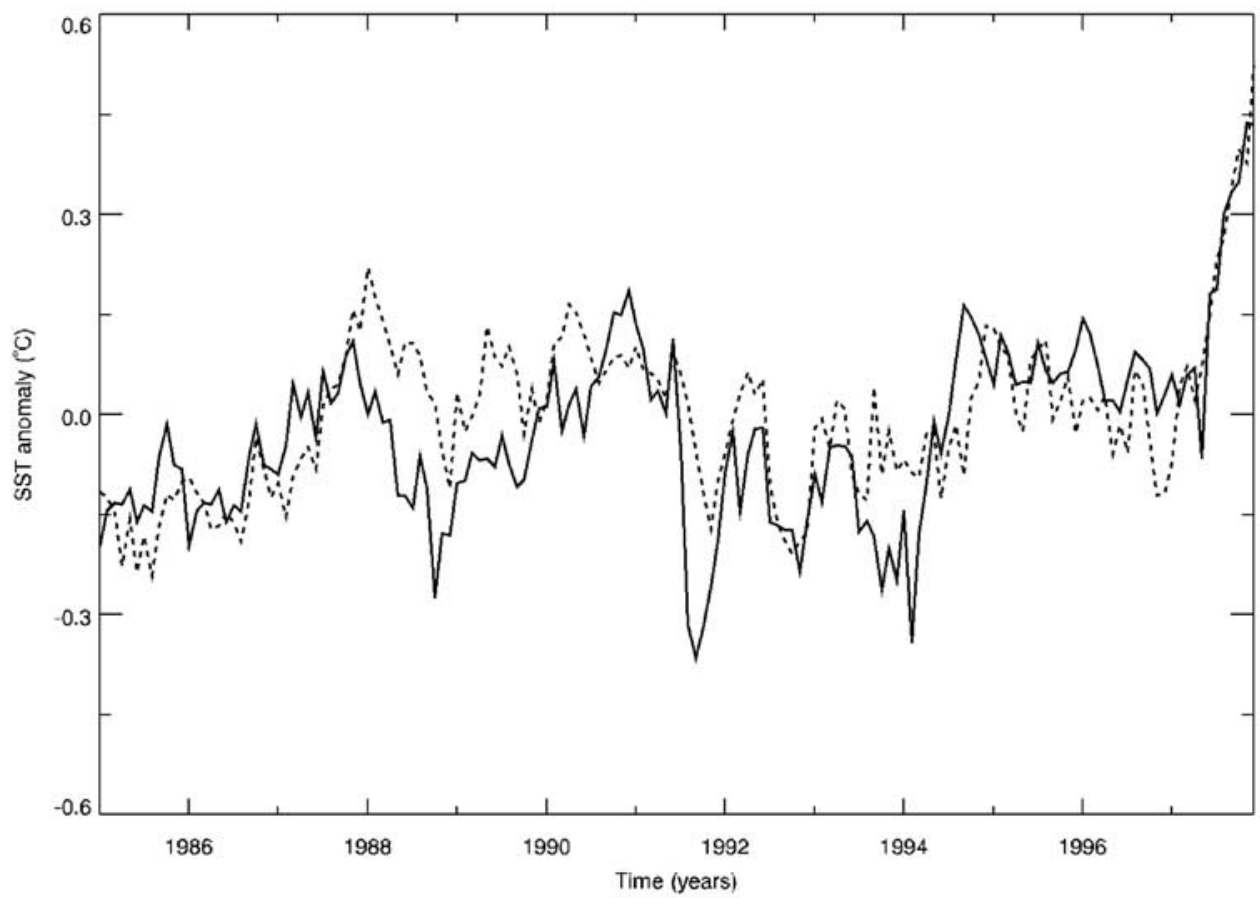

Figure 7. Time series of AVHRR (solid line) and COADS (dashed line) SST anomalies during the period 1985-1997. The data have been smoothed for clarity using a six-point moving average. The two curves follow each other closely, with a correlation coefficient of 0.77 .

over this 48-month period. This remarkably high value illustrates the phase relationship between the two data sets, in which rises and falls in COADS data are matched closely by those in AVHRR.

[50] The behavior of SST anomalies in AVHRR or COADS is different than that exhibited by ATSR (see Figure 6), in which anomalies depart from the AVHRR time series during May 1993. While there are differences in the times at which the SST anomalies rise and fall during Pinatubo, the rate of change in ATSR anomalies is similar to that displayed in AVHRR. The indication appears to be that the cooling/warming phase during 1991-1994 is captured by ATSR, but that either the dual-angle view or the SST retrieval process could be underemphasizing the extent of the cool phase represented in AVHRR or COADS data. Nevertheless, the conclusion in this comparison with in situ data is that both AVHRR and ATSR record climate variations well and are therefore useful in establishing global climate trends.

\subsection{Trend Analysis After Removing El Niño Signal}

[51] In order to explore climate trends further, we take the SST anomalies outlined above and remove the effects of El Niño using the method described in section 3. Figure 8a shows the global SST anomaly field for December 1997 after the removal of El Niño, derived from AVHRR, and Figure $8 \mathrm{~b}$ shows the difference between this and the original field (Figure 1b). The indication is that El Niño was successfully removed from these data. We also analyzed ATSR data in the same way, with similar results. Figure 9 shows the globally averaged anomalies (seasonal cycle and El Niño removed) for AVHRR (solid line) and ATSR (dashed line). For clarity, a 12-point moving average was used to remove higherfrequency variations from the data.

[52] To demonstrate any trend, we fit a straight line through the data. Not only are the anomalies from AVHRR and ATSR qualitatively similar, particularly during 19962000, but also the trend lines have a comparable gradient (in units of ${ }^{\circ} \mathrm{C}$ per decade) of 0.09 (AVHRR) and 0.13 (ATSR). We note here that if we add $0.15^{\circ} \mathrm{C}$ to ATSR-2 data prior to the removal of El Niño, as discussed in the context of Figure 6 , we obtain much closer agreement between AVHRR and ATSR, with ATSR providing a trend estimate of $0.09^{\circ} \mathrm{C}$ per decade identical to that of AVHRR.

[53] In the case of both AVHRR and ATSR, excursions from the straight line are similar in magnitude to the estimate of trend during the period of this study. In order to determine the validity of fit and the accuracy of fit coefficients, we adopt the method of Casey and Cornillon [2001] to estimate the standard error in the globally averaged data. The average error was found to be $0.16^{\circ} \mathrm{C}$ for AVHRR data and $0.14^{\circ} \mathrm{C}$ for ATSR. In the case of both AVHRR and ATSR the goodness-of-fit parameters were close to unity, indicating that given the above errors, the estimates of trends using these satellite data are reasonable. The associated error in the straight-line fit coefficients was found to be $0.03^{\circ} \mathrm{C}$ per decade for AVHRR and $0.06^{\circ} \mathrm{C}$ per decade for ATSR. These values agree well with the errors estimated by Casey and Cornillon [2001] for surface data. Subject to these errors, the trends estimated from AVHRR or ATSR are consistent with each other and also with estimates from other sources. The Intergovernmental Panel on Climate Change (IPCC) report [Houghton et al., 2001] gives a value of about $0.06 \pm 0.02^{\circ} \mathrm{C}$ per decade, estimated from a wide range of in situ data over the period 1860 to 

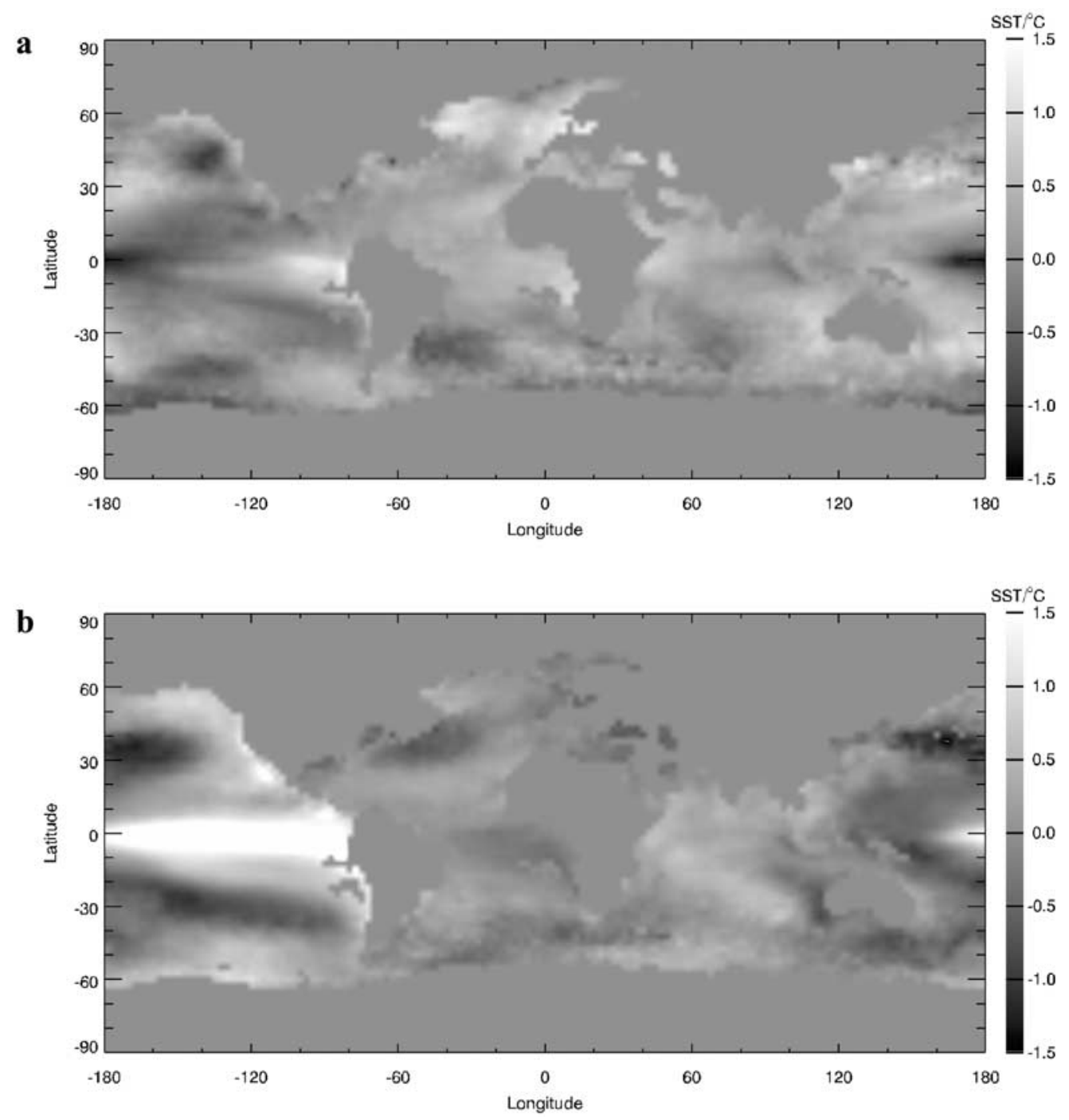

Figure 8. (a) Global SST anomaly field after the removal of El Niño for December 1997 and (b) the difference between this and the original field. The color bar scale representing temperature in ${ }^{\circ} \mathrm{C}$ is the same for both plots. These plots were derived from AVHRR data, but similar results are obtained from ATSR. The plots illustrate the reduction of El Niño during this month by regression onto the first principal component. See color version of this figure in the HTML.

2000. Using data from 1960 to 1990 , Casey and Cornillon [2001] obtained a trend estimate of $0.09 \pm 0.03^{\circ} \mathrm{C}$ per decade from long-term COADS data and $0.14 \pm 0.04^{\circ} \mathrm{C}$ per decade from the World Ocean Atlas. An average of values taken from Andersen et al. [2002] yields $0.1^{\circ} \mathrm{C}$ per decade for ATSR over the period August 1991 to June 1998, agreeing well with previous studies.

\subsection{Effects of El Niño on Patterns of Climate Change}

[54] The discussion thus far has surrounded a time series analysis of globally averaged data. It is interesting to investigate also patterns of climate variability and change, for which satellite data are particularly useful, since they provide data that are consistent, continuous, and global in nature. As part of our investigation, we analyzed the effect of El Niño upon the global patterns of SST variability during 1997/1998. An interesting result of this is that the high SST anomaly occurring during 1997 (Figure 6) is biased by a general increase in surface temperature globally during that year. Removing only the equatorial Pacific component reduces the global average temperature anomaly, but only by about $35 \%$. The remaining $65 \%$ of the warming during 1997 comes from regions outside the tropical Pacific, as illustrated in Figure 10, which shows the global SST anomaly (seasonal cycle only removed) for December 1997 using AVHRR data. The additional in-crease in SST occurs over parts of the Indian Ocean, particularly off the Somalian coast, the extratropical north and south Pacific, and with a component along the eastern boundary of the Pacific possibly associated with Kelvin wave activity, or more likely related to a mass movement of water associated with changes in trade winds. In order to remove the effects of El Niño more completely from the global data, we must take the approach that led to Figure 9 of projecting the first principal component onto each data point globally, rather than just over the tropical Pacific. 


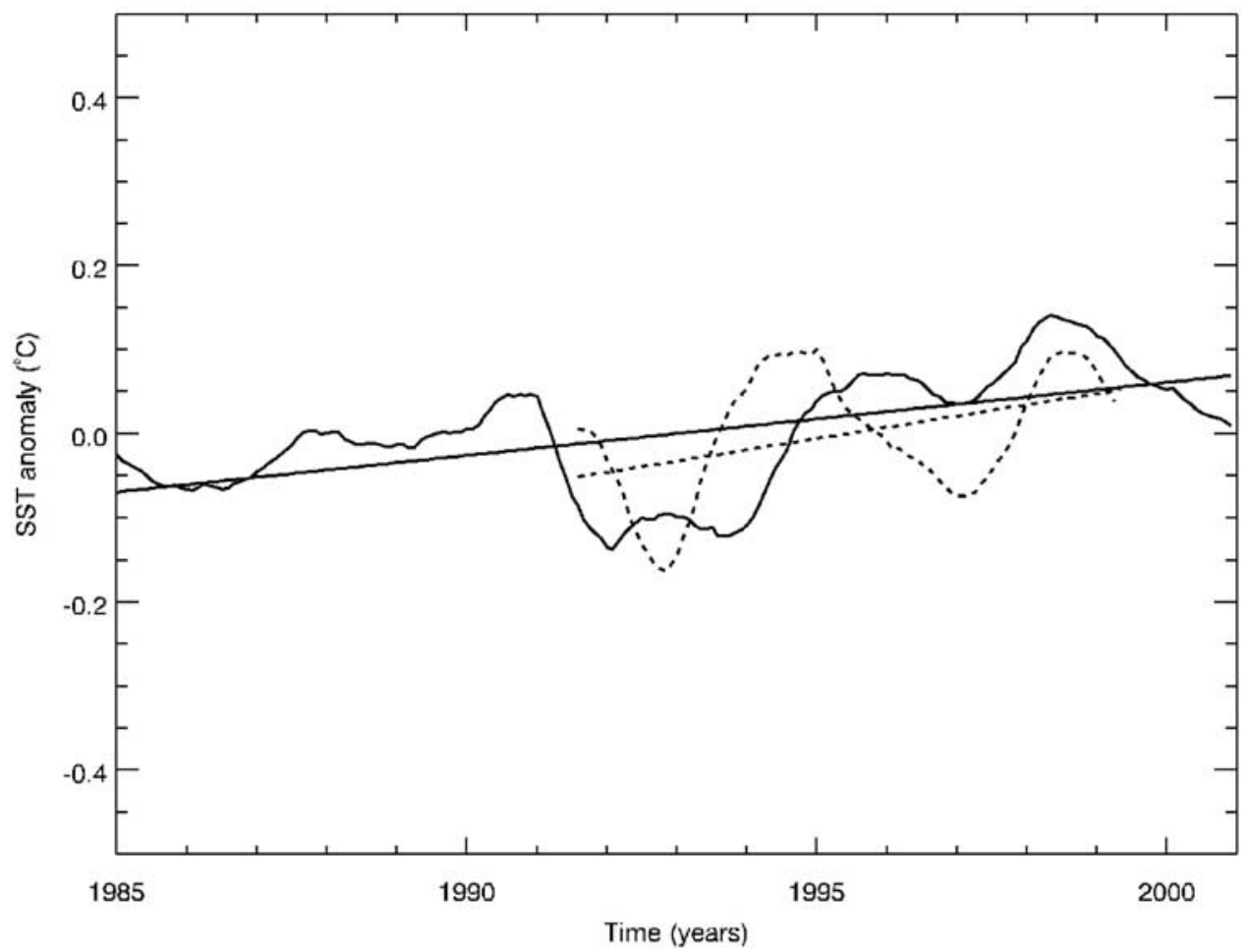

Figure 9. Globally averaged anomalies after removal of the seasonal cycle and El Niño for AVHRR (solid line) and ATSR (dashed line). For clarity, a 12-point moving average was used to remove higherfrequency variations from the data. The reduction in El Niño anomalies can be seen by comparison with Figure 6, which has the same vertical axis scale. The trend lines for AVHRR and ATSR for Figure 9a are 0.09 and $0.13^{\circ} \mathrm{C}$ per decade, respectively.

[55] We obtain a similar result using ATSR data, which, together with the fact that we see no such high global anomalies during other El Niño years, may indicate that this is a real climatic effect rather than it being a product of our analysis. Hansen et al. [1999] identified a similar warming in analyzed data from the Goddard Institute for Space Studies model (GISS) [Hansen et al., 1983], suggesting that this is due to decadal scale processes in the oceans. This

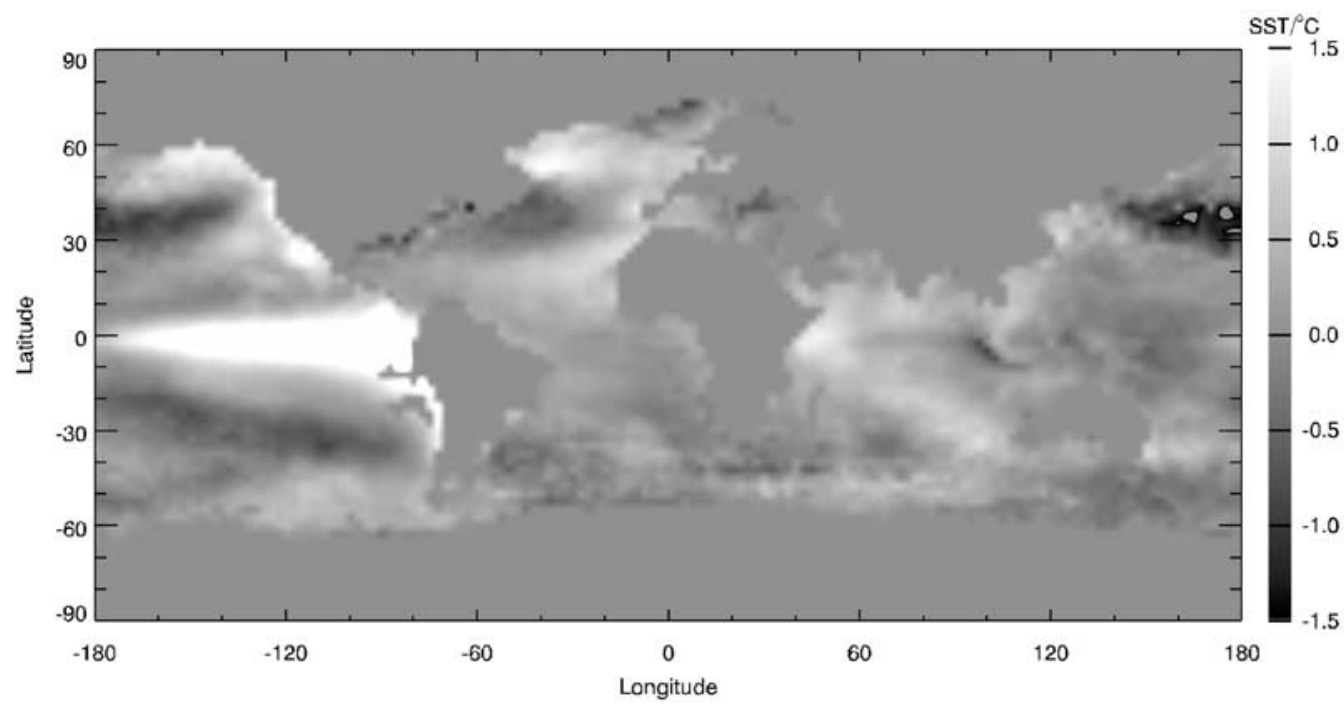

Figure 10. Global SST anomaly for December 1997 when the seasonal cycle only is removed from AVHRR data. The plot illustrates warming across the globe that may be associated with El Niño. In particular, there is an increase in SST over parts of the Indian Ocean, and the extratropical north and south Pacific. The color bar scale is in ${ }^{\circ} \mathrm{C}$. See color version of this figure in the HTML. 


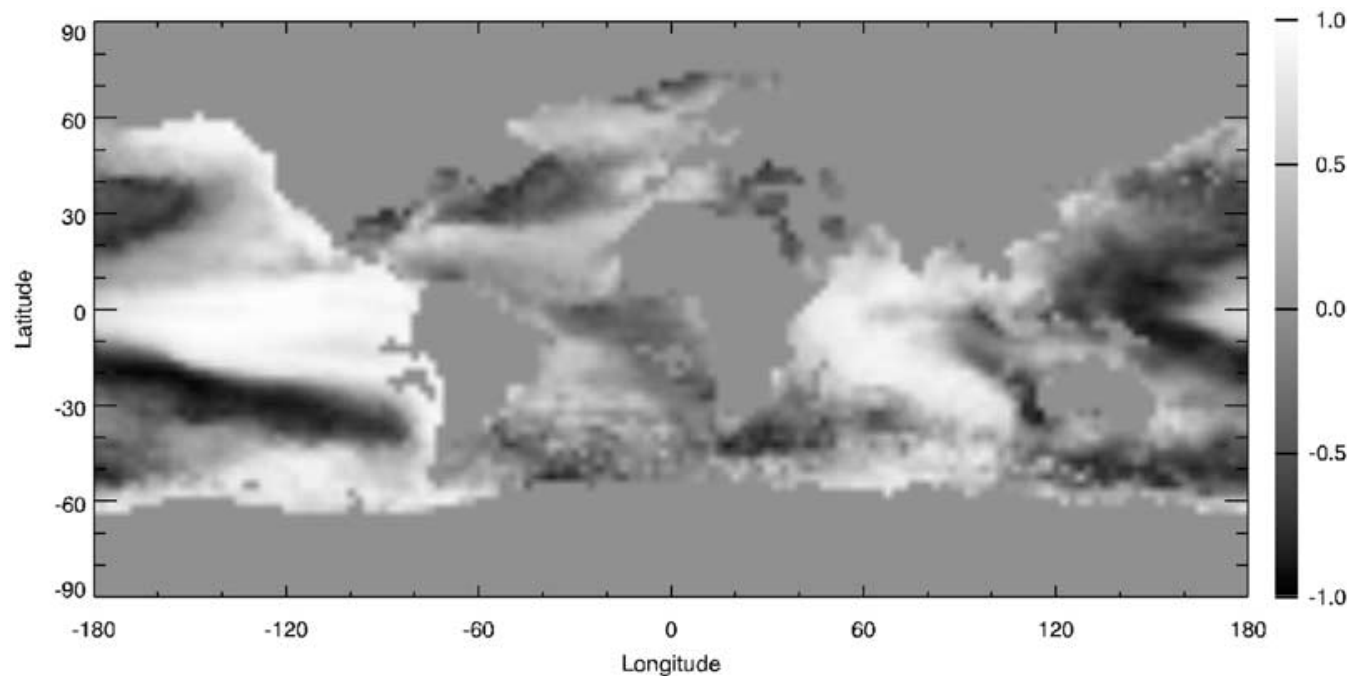

Figure 11. Correlation plot of sea-surface temperature anomaly (seasonal cycle only removed) with the first principal component (January 1994 to December 2000) associated with El Niño. Correlations higher than 0.9 indicate a time variability similar to that of the 1997 El Niño. These high correlations occur over regions of positive SST anomaly shown in Figure 10. See color version of this figure in the HTML.

may be the case; however, it is interesting to note that we can see a possible global impact of the 1997 El Niño event if we further analyze AVHRR data. Figure 11 shows a correlation plot of SST anomaly (seasonal cycle only removed) with the first principal component (that is, associated with El Niño). In order to highlight possible global effects of the 1997 El Niño, we use principal component data over the range January 1994 to December 2000, i.e., eliminating data occurring during Mount Pinatubo. Correlations higher than 0.9 occur over the regions highlighted for Figure 10, indicating a time variability there that is similar to that of the $1997 \mathrm{El} \mathrm{Niño.} \mathrm{It} \mathrm{is} \mathrm{therefore} \mathrm{possible}$ that the processes leading to the warming of the tropical Pacific due to an intensification of Pacific SSTs during 1997 are also contributing to an increase in temperature on a more global scale. However, whether El Niño-related processes have indeed led to the global high SST anomaly during 1997/1998, as found in the time series of Figure 6, is ambiguous in this analysis. In addition to high positive correlations, we also find high negative correlations, particularly over the Atlantic Ocean. Therefore the variability there is in anti-phase with El Niño. Using GISS data, Hansen et al. [1999] also identified a cooling of the Atlantic during El Niño, with which our results are in good agreement.

[56] Further evidence of an increased SST globally due to El Niño comes from an analysis of SST anomaly (seasonal cycle only removed) for October 1998 (Figure 12), which indicates a high SST anomaly over the whole of the Atlantic Ocean. If we plot a correlation map between SST anomaly

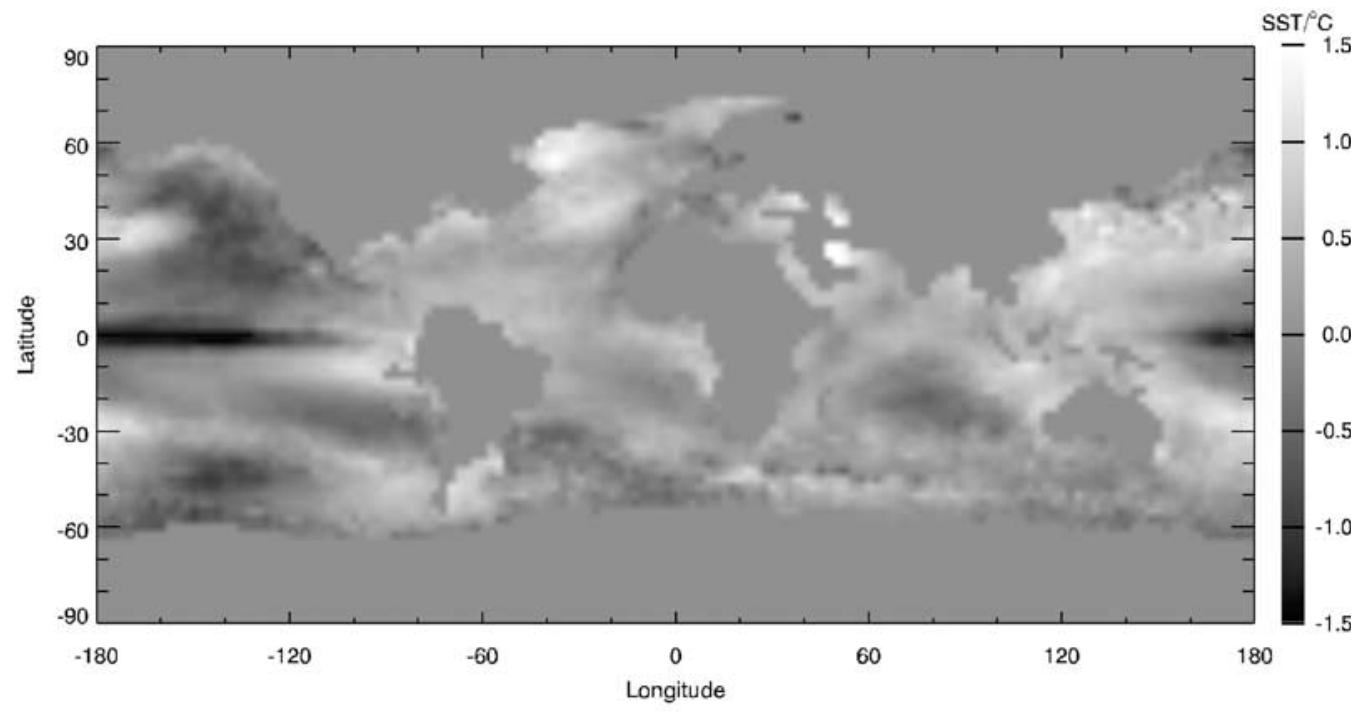

Figure 12. Sea-surface temperature anomaly for October 1998, obtained by removal of the seasonal cycle. A high SST anomaly occurs over much of the Atlantic Ocean. The color bar scale is in ${ }^{\circ} \mathrm{C}$. See color version of this figure in the HTML. 


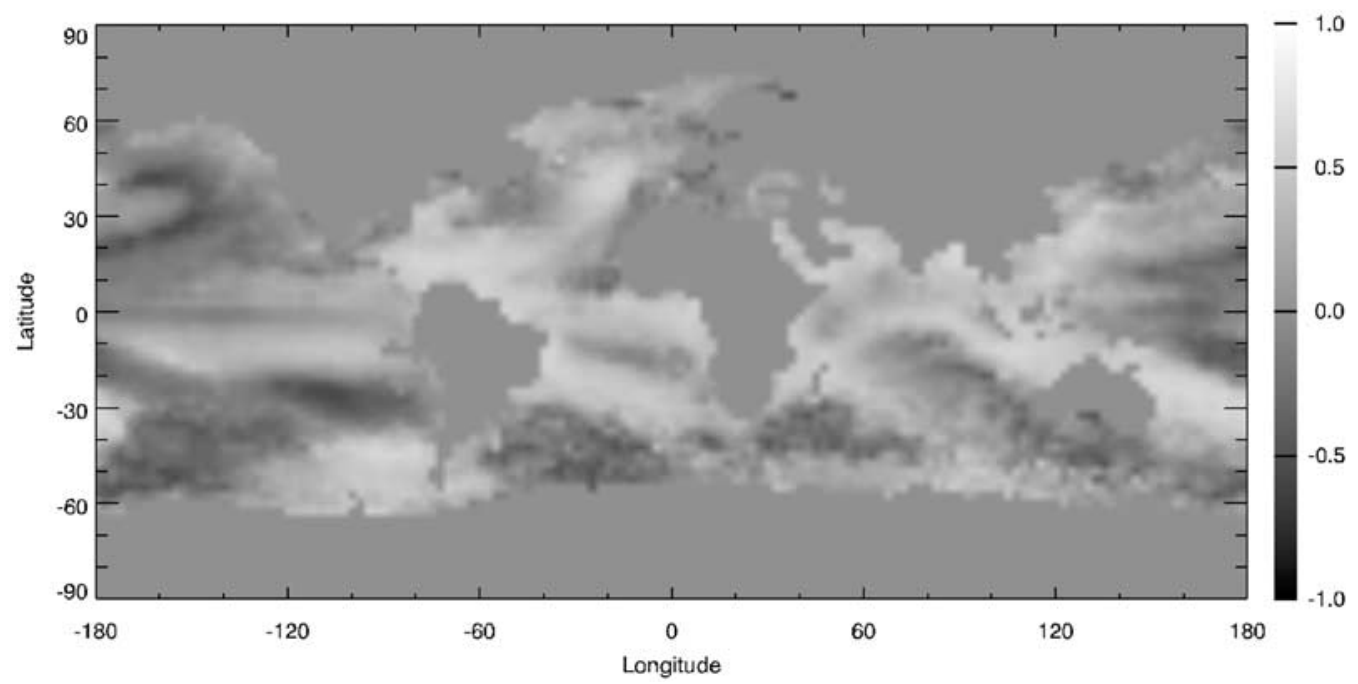

Figure 13. A correlation map between SST anomaly and the first principal component associated with El Niño (January 1996 to December 2000). Maximum correlations of greater than 0.9 occur over much of the Atlantic at a lag of 10 months, which corresponds to the timing between the maximum of El Niño during December 1997 and the high Atlantic SST variability found in Figure 12. This may be indicative of SST variability over the Atlantic that is similar to that of El Niño, at a lag of 10 months. See color version of this figure in the HTML.

and the first principal component, we find maximum correlations of greater than 0.9 over much of the Atlantic, including the extratropics, at a lag of 10 months, as illustrated in Figure 13. This lag corresponds to the timing between the maximum of El Niño during December 1997 (see Figure 6) and the high Atlantic SST variability found in Figure 12. We again reason that the temporal variability of SSTs over the Atlantic is similar to that of El Niño, this time lagging by 10 months. A conclusion one could draw is that El Niño is influencing SST globally, with a lag that could depend upon teleconnection timescales. As commented previously, it is uncertain whether El Niño has indeed influenced SST globally, although a modeling study or investigation of analyzed data could provide further clues as to the causes of increased SST globally during 1997/ 1998, as discussed also by Hansen et al. [1999]. However, even a simple comparison of SST in Figure 1a (October 1996) with Figure 1b (October 1997) does indicate an increase in SST globally, and it is this increase that comes out in our analysis.

\section{Discussion and Conclusions}

[57] We have investigated climate trends, using two independent satellite SST data-sets. After removing the seasonal cycle and effects due to El Niño, the temperature anomalies during the overlap period in the two data sets exhibit similar features after the Mount Pinatubo eruption. We deduce an ocean SST increase of $0.09 \pm 0.03^{\circ} \mathrm{C}$ per decade for AVHRR and $0.13 \pm 0.06^{\circ} \mathrm{C}$ per decade for ATSR, indicating some consistency between these instruments and also with previous studies.

[58] The trend of increasing temperature apparent in Figure 9 is due to one or more of the following: instrumental drift, residual effects of El Niño, effects of Pinatubo aerosols, the processing method used to derive the SSTs from satellite, natural climatic processes, or human-induced climate change. We explore each of these, in turn, below.

[59] One important aspect of our work was the comparison of three data sets, two from satellite sensors and one from in situ measurements. In comparing these data, we were able to conclude that diurnal variations were adequately removed and that the observed climate variations are realistic, rather than relating to a characteristic of the measurement system. Therefore the first of these reasons for a positive trend, that of instrumental drift, we can perhaps discount, since we are using independent measurement systems, which give similar results.

[60] As regards the second point, there is the possibility that the AVHRR warm anomaly of $0.14^{\circ} \mathrm{C}$ during 1998 in Figure 9 may be due to an El Niño remnant. On the other hand, it may be equally true that it is due to processes other than El Niño. However, artificially reducing this component to zero over the period 1996-2000 (i.e., one third of the whole data range) nevertheless gives a warming trend of $0.04^{\circ} \mathrm{C}$ per decade, which is still significant.

[61] With regard to the effects of the Pinatubo aerosols on the satellite measurement, we note that a comparison of the AVHRR time series with in situ data from COADS indicates a time variation of cooling/warming during 1991-1994 that is very consistent. Notwithstanding any differences between COADS and ATSR, particularly during Pinatubo, the conclusion in section 4 was that all three data sets provide accurate measurements that are useful in global change analyses, despite the cooling due to Pinatubo.

[62] The fourth point, namely the effects of processing methodology, is the most difficult to assess. One problem is that we are examining climate trends with a gradient of the same order as the maximum excursions in the data, and one could suppose that these excursions occur due to the SST retrieval. If it were the retrieval that gives rise to the fluctuations found in Figure 9, we presume that independent instruments would provide an anomaly time series that 
exhibits different characteristics. Since the anomaly time series from AVHRR and ATSR yield similar results, we reason that the trend we have calculated is associated more with natural climatic processes and fluctuations rather than with the instrument or the processing of SSTs. Certainly, the fact that the anomalies in Figure 9 are so similar for both instruments is unexpected and encouraging, and perhaps indicates that we are seeing a true trend toward increased ocean temperatures or else atmospheric effects that influence AVHRR and ATSR to almost the same degree, which would be surprising given the differences between the instruments and retrieval methodology. This latter point is particularly unlikely given the close correspondence between COADS and AVHRR SSTs.

[63] Therefore we conclude that the positive trend seen in Figure 9 is representative of a true increase in ocean SST, especially as the trends in AVHRR and ATSR data are similar. However, within the scope of this analysis, it is not possible to deduce whether this trend is due to natural or human-induced processes, or whether the trend is simply a manifestation of the fluctuations in the anomaly time series. A related point of concern is whether or not effects from $\mathrm{La}$ Niña provide a cooling of global SST that is reflected in the time series, but not in our analysis methodology. However, La Niña does not occur at the same times as cool phases in Figure 9, and so we discount this possibility. It is interesting to note here that plans are being developed to reprocess ATSR data, so that it will be possible to undertake a study similar to this one with a longer and very consistent set of data. Using these data and comparing with the already available AVHRR data, it should be possible to allow for the effects of La Niña, in a similar way as was done for El Niño.

[64] One important aspect of our analysis (and indeed many analyses of satellite-derived SST) is that fluctuations in the anomalies are larger than the derived trend, putting some limit upon the accuracy of the trend. As pointed out, these fluctuations may be natural in origin, so that any observing system will be affected in a similar way. However, the error analysis that we performed when estimating the trend line provides an error in trend of about $0.03^{\circ} \mathrm{C}$ per decade, indicating an increase in SST of at least $0.06^{\circ} \mathrm{C}$ per decade obtained from these satellite data. Therefore, when the fluctuations about the trend line are natural, the globally averaged SST field obtained from these satellite data is nevertheless increasing by this amount overall, over the period of our data, regardless of the processes that drive that trend. Furthermore, if we propose the techniques and results given here as a "proof of concept" exercise, then the longer-term measurements to be provided by satellites in the future should help to make the estimates more accurate. At present, the results we have provided can be used for comparison with independent observations and model results to give more confidence in the variability and trends derived from other data sources, such as those used by the IPCC and other organizations.

[65] Finally, we have started to investigate spatial patterns associated with the temperature anomalies. Specifically, we looked at possible global effects of El Niño and concluded that the 1997 event appears to have affected SST globally at lead times of up to 10 months. We partially took these effects into account by a lag 0 regression of SSTs onto the first principal component associated with El Niño. Whatever the causes of the high global SST anomalies during $1997 / 1998$ identified in Figures 10-13, it is clear that the effects need to be taken into account when investigating climate change. For example, if it is anthropogenic change that is under consideration, then allowance may need to be made for natural processes such as El Niño, as was done here.

[66] In conclusion, we suggest that this analysis of global satellite data provides new quantitative details of global climate change unavailable through any other observational means. We are able not only to generate an estimate of global SST trend, but also to begin to analyze spatial patterns of change. In this paper, we have analyzed the natural changes due to El Niño, and attempted to remove these to look at residual trends. However, it is clear that a great deal of further work remains, particularly as regards the fingerprinting of climate change. In a further paper, we hope to revisit this aspect, comparing patterns of change with those from long-term predictions.

[67] Acknowledgments. The AVHRR Oceans Pathfinder SST data were obtained from the Physical Oceanography Distributed Active Archive Center (PO-DAAC) at the NASA Jet Propulsion Laboratory, Pasadena, California (http://podaac.jpl.nasa.gov). We acknowledge the Rutherford Appleton Laboratory, ESA, and the NERC Post-Launch Support Programme at RAL, through which the ATSR data products were supplied.

\section{References}

Allen, M. R., C. T. Mutlow, G. M. C. Blumberg, J. R. Christy, R. T. McNider, and D. T. Llewellyn-Jones (1994), Global change detection, Nature, 370, 24-25.

Andersen, O. B., P. Knudsen, and B. Beckley (2002), Monitoring sea-level and sea-surface temperature trends from ERS satellites, Phys. Chem. Earth, 27, 1413-1417.

Casey, K. S., and P. Cornillon (2001), Global and regional sea surface temperature trends, J. Clim., 14, 3801-3818.

Christy, J. R., and R. T. McNider (1994), Satellite greenhouse signal, Nature, 367, 325

Corti, S., F. Molteni, and T. N. Palmer (1999), Signature of recent climate change in frequencies of natural atmospheric circulation regimes, Nature, 398, 799-802.

Cracknell, A. P. (1997), The Advanced Very High Resolution Radiometer, Taylor and Francis, Philadelphia, $\mathrm{Pa}$

Donlon, C. J., T. J. Nightingale, T. Sheasby, J. Turner, I. S. Robinson, and W. J. Emery (1999), Implications of the oceanic thermal skin temperature deviation at high wind speed, Geophys. Res. Lett., 26, 2505-2508.

Edwards, T., et al. (1990), The Along Track Scanning Radiometer measurement of sea-surface temperature from ERS-1, J. Br. Interplanet. Soc., 43, $160-180$.

Enfield, D. B., and A. M. Mestas-Nunez (1999), Multiscale variabilities in global sea surface temperatures and their relationships with tropospheric climate patterns, J. Clim., 12, 2719-2733.

Evans, R., and G. Podesta (1996), AVHRR Pathfinder SST approach and results, Eos Trans. AGU, 77(46), Fall Meet Suppl., F354.

Hansen, J., G. Russell, D. Rind, P. Stone, A. Lacis, S. Lebedeff, R. Ruedy, and L. Travis (1983), Efficient three-dimensional global models for climate studies: Models I and II, Mon. Weather Rev., 111, 609-662.

Hansen, J., R. Ruedy, J. Glascoe, and M. Sato (1999), GISS analysis of surface temperature change, J. Geophys. Res., 104, 30,997-31,022.

Hansen, J., R. Ruedy, M. Sato, M. Imhoff, W. Lawrence, D. Easterling, T. Peterson, and T. Karl (2001), A closer look at United States and global surface temperature change, J. Geophys. Res., 106, 23,947-23,963.

Houghton, J. T., et al. (Eds.) (2001), Climate Change 2001, Cambridge Univ. Press, New York.

Hurrel, J. W., and K. E. Trenberth (1997), Spurious trends in satellite MSU temperatures from merging different satellite records, Nature, 386, 164167.

Kidwell, K. (1995), NOAA Polar Orbiter User's Guide, Natl. Clim. Data Cent., Washington, D. C. (Available at http://www2.ncdc.noaa.gov/POD) Kilpatrick, K. A., G. P. Podesta, and R. Evans (2001), Overview of the NOAA/NASA Advanced Very High Resolution Radiometer Pathfinder 
algorithm for sea surface temperature and associated matchup database, J. Geophys. Res., 106(C5), 9179-9197.

Palmer, T. N. (1999), A nonlinear dynamical perspective on climate change, Weather, 48, 313-348.

Rao, C. R. N. (1993), Degradation of the visible and near-infrared channels of the Advanced Very High Resolution Radiometer on the NOAA-9 spacecraft: Assessment and recommendations for corrections, NOAA Tech. Rep., NESDIS-70, 25 pp.

Reynolds, R. W., N. A. Rayner, T. M. Smith, D. C. Stokes, and W. Wang (2002), An improved in situ and satellite SST analysis for climate, J. Clim., 15, 1609-1625.

Salinger, M. J., R. E. Basher, B. B. Fitzharris, J. E. Hay, P. D. Jones, J. P. MacVeigh, and I. Scmidely-Leleu (1995), Climate trends in the southwest Pacific, Int. J. Climatol., 12, 285-302.

Schwalb, A. (1978), The TIROS-N/NOAA A-G Satellite Series, Tech.

Memo. NESS 95, Natl. Oceanic and Atmos. Admin., Silver Spring, Md.

Schwalb, A. (1982), Modified version of the TIROS N/NOAA A-G Satellite Series (NOAA E-J)—Advanced TIROS N (ATN), NOAA Tech. Memo. NESS 116, Natl. Oceanic and Atmos. Admin., Silver Spring, Md.
Vasquez, J., A. V. Tran, R. Sumagaysay, and E. Smith (1996), NOAA/NASA AVHRR Oceans Pathfinder Sea Surface Temperature User Reference Manual, Jet Propul. Lab., Pasadena, Calif.

Wigley, T. M. L. (2000), ENSO, volcanoes and record-breaking temperatures, Geophys. Res. Lett., 27, 4101-4104.

Woodruff, , S. D. R. J. Slutz, R. L. Jenne, and P. M. Steurer (1987), A comprehensive ocean-atmosphere data set, Bull. Am. Meteorol. Soc., 68, $1239-1250$.

Zhang, H.-M., R. W. Reynolds, and T. M. Smith (2004), Bias characteristics in the AVHRR sea surface temperature, Geophys. Res. Lett., 31, L01307, doi:10.1029/2003GL018804.

Zheng, X., R. E. Basher, and C. S. Thompson (1997), Trend detection in regional-mean temperature series: Maximum, minimum, mean, diurnal range and SST, J. Clim., 10, 317-326.

S. P. Lawrence, D. T. Llewellyn-Jones, and S. J. Smith, Department of Physics and Astronomy, Space Research Centre, University of Leicester, Leicester, LE1 7RH, UK. (sp15@le.ac.uk; dlj1@le.ac.uk; sts@star.le.ac.uk) 